\title{
Introduction
}

\section{Principal-agent theory and research policy: an introduction}

\section{Dietmar Braun and David H Guston}

The rational choice perspective is prominent in many sociological, economic and political science literature but has been undervalued until now in the field of science studies. This special issue attempts to revalorise this perspective by introducing the principal-agent theory with relation to research policy-making. The introduction presents the basic features of the model of principal-agent and reviews the theoretical development and applications in research policy. It summarises the main findings of the articles in this issue and concludes that the studies in the framework of principal-agent demonstrate the willingness of combining theoretical rigour and 'requisite variety' by applying the theory to a large number of different fields linked to research policy-making.

Professor Dietmar Braun is at the Institut d'Etudes Politiques et Internationales, Université de Lausanne, BFSH 2, CH-1015 Lausanne, Switzerland; Tel: +41 21 6923132; Fax: +41 21 6923145; E-mail: Dietmar.Braun@iepi.unil.ch. Professor David H Guston is in the Department of Public Policy, Rutgers, The State University of New Jersey, 33 Livingston Ave, Suite 202, New Brunswick, NJ 08901-1980 USA; Tel: +1 7329322499 707; Fax: +1 732932 1107; E-mail: guston@ rci.rutgers.edu.
$\Lambda$ LTHOUGH THEY HAVE never played a prominent role in the sociology of science or political science literature, studies on research policy-making have a long tradition. Furthermore, it must be stated that a common theoretical framework has been lacking. The field is, as David Guston (1996) noticed, heavily "undertheorised". It would be wrong, however, to assume that there were no attempts in the past to learn lessons about research policies on the base of various theoretical approaches. Though a systematic and historical overview is lacking, we can discern perhaps five theoretical currents that have influenced in some way the thinking on research policies:

- Economics, both classical (Polanyi, 1951; 1962; Tullock, 1966; Ghiselin, 1987; Foray, 2000) and Marxist (Bourdieu, 1975; Bourdieu, 2001);

- System-theory (Krohn and Küppers, 1987; Luhmann, 1990);

- Constructivism (Latour and Woolgar, 1979; Knorr et al, 1981; Knorr-Cetina, 1981; Latour, 1987);

- Institutionalism (Merton, 1970 [1938]; BenDavid, 1971; 1991; 1991 [1977]; Mukerji, 1989; Mayntz, 1991);

- Discussion on the "finalization of science" (Daehle, 1979; Weingart, 1997).

This introduction is not the place to assess the contribution of each approach to our present knowledge on research policies. We generally believe, however, that these approaches are either too abstract (systemtheory), lacking in parsimony or theoretical rigour (constructivism, institutionalism, finalization) or, if they are parsimonious (like classical economics), that they abstract too greatly from the 'requisite variety' of real life. 
Dietmar Braun, professor of comparative political science at the Institut d'Etudes Politiques et Internationales of the University of Lausanne (Switzerland), has studied political sciences at the University of Amsterdam (PhD) before he worked as a research fellow at the Max Planck Institute for Societal Research in Germany. In 1996, he presented his habilitation thesis at the Institute for Political Science at the University of Heidelberg before he became, in October 1996, full professor in Lausanne. Dietmar Braun has published on labour market, higher education and research policies, federalism as well as on modern political theory. He has published several books, and articles in journals.

David $\mathrm{H}$ Guston is associate professor and director of the Public Policy Program at the Bloustein School of Planning and Public Policy at Rutgers University. His book, Between Politics and Science (Cambridge University Press, 2000) was awarded the 2002 Don K Price Prize by the American Political Science Association for best book in science and technology policy. His published work focuses on research and development policy, scientific integrity and responsibility, science advice and public participation in technical decision making, peer review, and the politics of science policy. His current research includes investigating the public value of social policy research sponsored by US federal social policy agencies.

What we need instead, is an intelligent combination of analytical and rigorous tools, of "parsimony, refinement, and (in the sense used by mathematicians) elegance" (Bates et al, 1998, page 11). Such tools will be useful for interpreting research policies with attention to the historical and institutional contexts in which research policy is made, something we find for example in the concept of "analytic narratives" developed by Bates et al (1998).

The analytic tool most useful for this purpose seems to us to be principal-agent theory, which has been developed in the context of rational choice and transaction cost theory (see, for example, Ross, 1973; Williamson, 1975; 1985; Coleman, 1990; Kiewiet and McCubbins, 1991). In the early 1990s, Braun (1993) introduced the concept in the context of research policy-making (see below), most notably by referring to the relationship between policymakers as the principal and the various funding agencies responsible for the implementation of research policy as the agents. This relationship seemed to correspond perfectly to the basic logic of principal-agent figurations, that is, one actor who seeks "extension of self" (Coleman, 1990, page 146) by delegating some tasks for execution by other actors who seem better capable to do so.

Funding agencies were, since their origins, designed to work out and implement research policies, in preference to the usual public bureaucracy that lacked the necessary direct contacts with science. The concept is, however, more general and can, as will be shown in this special issue, be applied to relations between policy-makers and scientists in general, between the funding administration and scientists, or between funding programme directors and scientists.

Principal-agent theory is becoming a predominant approach in different fields of political science where 'delegation' as one particular form of organising state activities is discussed. This predominance holds for studies of delegation to bureaucracy by Congress (McCubbins, 1984; Weingast, 1984), delegation to "independent regulatory agencies" (Majone, 2001a) and central banks (Majone, 2001b; Elgie, 2002), as well as of all relations in the "democratic chain of delegation" from the voter to the implementing bureaucracy (Strom, 2000). Given the extant literature on principal-agent theory in research policy, we consider it appropriate to demonstrate the usefulness of the approach in this policy field and to further elaborate the concept.

We want, first, to briefly introduce the reader to the basics of principal-agent ideas before we then present the findings on research policy in the literature. Finally, we will give an overview of the main themes discussed in this special issue.

\section{Basics of principal-agent theory}

The principal-agent literature deals with a specific social relationship, that is, delegation, in which two actors are involved in an exchange of resources. The principal is the actor who disposes of a number of resources but "not those of the appropriate kind to realize the interests (for example, has money but not the appropriate skills)" (Coleman, 1990, page 146). $\mathrm{He}$ or she then needs the agent, who accepts these appropriate resources and is willing to further the interests of the principal. In this sense, Coleman is right to speak of an "extension of self" of the principal by way of delegation.

The principal-agent model has been developed within the framework of the "new institutional economics" (Williamson, 1975; 1985; Moe, 1984; Miller, 1992) and therefore shares the basic characteristics of this framework, for instance, the assumption of rational actors striving to maximise their preferences that are ordered according to their priorities. Institutions can constrain actors' choices so that the conscious design of institutions (like contracts) may help to overcome typical collective action problems involved in the principal-agent relationship.

There are two typical collective action problems discussed in the literature - moral hazard and adverse selection. These problems are based on what the new institutional economics calls the 'opportunism' of actors: Actors are self-interested and thus seek to maximise their personal welfare. They may do this by seeking their self-interest "with guile. This includes but is scarcely limited to more blatant forms, such as lying, stealing, and cheating" (Williamson, 1985, page 47).

In the particular case of principal-agent relations, such 'cheating' or, as is often said, 'shirking' by the agent may happen because the agent usually has an informational advantage vis-à-vis the principal. The principal does not know for sure if the agent will really do his or her best when delegated certain tasks 
(this is the "moral hazard"), and usually the principal does not have sufficient information on the abilities of potential agents to find the one best suited to do the task (this is "adverse selection").

As agents seek their self-interest with guile, they may hide this information from the principal to reduce their work load or to be hired in the first place. The resulting delegation could then be sub-optimal or even detrimental to what the principal attempted to achieve. This is why the principal-agent literature (discussing the problems of insurance agencies or of parliaments dealing with bureaucracies) discusses contract and monitoring mechanisms designed to avoid these problems.

The collective action problems arise as both sides - the principal and the agent - have an interest in entering into the exchange relationship. They both profit by exchanging resources: the principal by getting something done he or she could not otherwise do, and the agent because he or she gets remuneration of some kind (money, social recognition, and so on). Despite these mutual advantages, the collective outcome may be suboptimal because, as is said, the agent has incentives to seek his self-interest with guile.

We should also not forget the possibility of the principal to 'shirk', a possibility often not discussed in the literature. He or she may have incentives not to deliver the resources fully as agreed to in the contract. Because of these co-operative and selfish motives characterising the relationship, principal-agent interaction is a 'mixed-motive game'.

The principal-agent literature discusses not only contract and monitoring mechanisms but also different possible configurations and their influence on the shirking of agents. A configuration reducing the possibilities to shirk, for example, is the presence of multiple agents (Kiewiet and McCubbins, 1991; Ferejohn, 1993), which creates more of a marketlike structure. The more advantageous configuration for the agents of multiple principals has been less often discussed (but see Elgie, 2002).

\section{Principal-agent theory enters science policy}

Principal-agent theory began to enter science policy in the 1990s. Guston (1996) wanted to use it to "reinterpret" generic science policy problems. For him, "the problem of science policy is the problem of delegation" because lack of information on the side of "non-scientists" leads to the typical problems of adverse selection and moral hazard. This formulation provides the opportunity to reflect about adequate incentive structures to solve the main problems in science policy such as the integrity and productivity of research, or the choice between mission and disciplinary research.

The main thrust of his paper was to make understood that treating scientists as agents does not at all mean a hierarchical relationship. The autonomy of

\section{A configuration reducing the possibilities of agents shirking is the presence of multiple agents, which creates more of a market-like structure: the more advantageous configuration for the agents of multiple principals has been less often discussed}

agents is widely respected in this relationship, and one should consider the relation between policymakers and scientists as a "two-way street" where a certain degree of autonomy is respected on both sides.

Neither does Guston want to defend the usual normative stance of the principal-agent literature, which is to inform the principal about how best to design incentive structures. Principal-agent can be used for a variety of purposes and illuminate the basic tensions in the generic problems mentioned above, and it can be used to reflect in general on the "fairness" of the contracts defined between the principal and the agent.

Guston applied principal-agent theory to the relationship between non-scientists and scientists in general. Most of the other literature - and Guston (2000) joins them later - deals with a very specific feature of science policy, that is, the use of research councils and funding agencies that intermediate between policy-makers on the one hand and scientific agencies and scientists on the other hand. The introduction of an intermediary level makes the discussion more complex. The central question becomes: in what way can research councils be seen as agencies that serve the interests of policy-makers?

The introduction of research councils can, from a functionalist perspective, be explained by the proximity of these agencies with the scientific field, more information on the field, and a greater capacity to aggregate the available knowledge. From an economic perspective, the establishment of funding agencies can be explained by the decrease in transaction costs for policy-makers in developing science policies. It seems, in addition, easier to influence such agencies that are either public or semi-public than to influence the scientists themselves because of the former's direct dependence and constitutional commitments to work in the interests of policymakers.

Principal-agent theory draws the attention of the observer immediately to the possibility of 'shirking' by research councils as agents. Since the beginning, however, contributions in science policy have explained such shirking not simply in terms of 
'opportunistic' behaviour but in relation to the interaction between funding agencies and scientists. Braun (1993) criticised the usual dyadic way of conceptualising principal-agent relationships and offered a theoretical account based on the "triadic relationship" among policy-makers, funding agencies and scientists.

His main argument is that funding agencies become intimately interwoven with the "third party" - an under-developed concept in principal-agent theory but already mentioned in the work of Coleman (1990) - to fulfil the task delegated by the policy-maker principal. We could conceptualise the triadic relationship by designing two separate principal-agent relationships, one between policymakers and the research council and one between the research council and scientists (see also Rip, 1994). Braun would find this too simple, however.

First, scientists are certainly not simply agents of research councils but have a high degree of autonomy and influence on what is decided in research councils. The same holds for the relationship between policy-makers and research councils. We should rather speak of interdependent relationships in which both sides have something necessary to offer the other and a certain degree of autonomy is crucial for all actors in the game. This is, in fact, the "two way relationship" Rip and van der Meulen (1996) evoke, only that we now have two "two way relationships'.

Second, each relationship is influenced by the way the relationship on the other side is organised. If funding agencies choose to 'shirk' in favour of the interests of scientists, this behaviour will have repercussions for the strategies of principals to organise the principal-agent relationship with research councils. If policy-makers are using their formal authority to oblige funding agencies to comply with political interests, this will have implications for the way scientists co-operate with research councils. In such dual interdependent relationships, research councils fare best when they are able to balance the often opposed interests of scientists and policymakers. Such balancing demands a considerable degree of independence with respect to the principal and to the third party (see also Rip, 1994, page 13; Caswill, 1998).

Both Rip and Braun underline, in addition, the historical and institutional context that is decisive for how the triadic relationship has evolved. There were times, especially during the "science-push period" after World War II, when scientific interests became predominant and research councils seemed to be 'captured' by these interests. Today we seem to experience a period when research councils are more and more captured by political interests. Both periods have, or will, in the end, destabilise the triangle and will lead to increasing efforts of funding agencies to find a new equilibrium.

This idea of finding 'stable equilibria' in science policy principal-agent relationships was put forward in an analytical innovative way, by using game theory (which has found some attention recently in principal-agent literature (Huber and Lupia, 2001)) by van der Meulen (1998). He does not deal with the triadic relationship but instead discusses the "basic" relationship between policy-makers and scientists.

He demonstrates two things: first, that given the utility functions of both the principal and the agent and their options (the principal: to trust or to monitor; the agent: to comply or not comply), the game does not find a stable Nash equilibrium. Each choice creates an incentive for at least one of the two actors to change the status quo. Nevertheless, and this is the second point, there are possibilities to find stable equilibria if we assume that, because of the interdependency of actors, the relationship is a long-term one and the game can become co-operative.

Van der Meulen sees four stabilising structures: the role of funding agencies, as discussed before, that can serve a balancing function; the mutual interest of scientists and policy-makers in using peer review; the emergence of a consensus on policy goals; and a competition among agents organised by the principal. For each structure, van der Meulen finds that scientists and policy-makers can develop an interest in co-operation instead of opportunism.

Finally, Guston (2000) also discusses stabilising arrangements in science policy, but finds them above all in the existence of "boundary organisations". His reasoning is influenced by the constructivist literature that he sees as a useful corrective to the often "stylistic" assumption of principal-agent theory. Within the constructivist approach, "boundary" is a term developed by Gieryn (1995) to characterise the often fluid and ambiguous demarcations between scientific and non-scientific fields.

Guston builds his boundary organisations on the notion of "boundary objects" that "allow members of different communities to work together around them, and yet maintain their disparate identities" (Guston, 2000, page 29). Boundary organisations can then be seen as situated between politics and science, both of which can be regarded as principals to the boundary organisations, and, "in doing so, [the boundary organisations] internalise the provisional and ambiguous character of that boundary". They fulfil, therefore, exactly the stabilising function that van der Meulen ascribes to funding agencies, and which is also alluded to in the texts of Braun and Rip.

Boundary organisations may also be of another kind: Guston (2000) treats the examples of the Office of Research Integrity and the Office of Technology Transfer in the United States. The most important point of his study is perhaps that he underlines - and this is the stabilising function of boundary organisations - the inherent capacity of these organisations to facilitate "co-production", that is, the creation of both "knowledge and social order" or, in other terms, both scientific and political interests. Because boundary organisations internalise the 
different logics of action, they can bridge different "worlds". The result of his study confirms that intermediary organisations and boundary organisations are crucial to stabilise, according to the logic of principal-agent theory, the inherent unstable relationship of politics and science.

The application of the principal-agent approach in this 'first wave' of science policy studies demonstrates that the theory is not applied without reflection and modifications. The 'field', in particular the position of intermediary organisations, provoked a more complex reflection, which led to the introduction of 'triadic relationships', 'boundary organisations', 'equilibria in games', and 'dynamics in interdependent relationships'.

\section{Principal-agent in science policy today}

This special issue unites most of the authors who have participated in the 'first wave' of publications and adds some others. The articles presented here demonstrate the attempt to broaden the field of application of principal-agent theory in science policy studies and brighten the interesting light this perspective can throw on the choices and procedures of science policy actors.

Braun elaborates the existing insight that historical periods in the funding of science create different utility functions for both political principals and scientific agents, which lead to various "games". The different periods of science policy-making after World War II are interpreted from the angle of principal-agent to see in what way the basic antinomy of funding policies (that is, the maintenance of the autonomy of scientists and the political interest to influence scientific action) is treated within these periods. His article ends by pointing to two different ways in today's research policies of organising the principal-agent relationship, either in a marketoriented way, which increases the moral hazard of scientists, or by funding inter-systemic networks, which seems to be a promising way to overcome the problem of moral hazard and monitoring costs in science policy.

Van der Meulen takes up the classical issue of the role of funding agencies. He increases, however, the complexity of the configurations these agencies have to deal with because recent developments in science policy have shown that users are becoming a kind of "fourth party" in the principal-agent game. By using an empirical study of the Norwegian Research Council, which comprises all types of funding under one roof (but in different divisions), he looks for the strategies that different divisions develop given the various configurations of actors they are dealing with. He finds that differences with respect to the acceptance of strategic funding given the contacts and relationships with users are indeed quite important. Actor constellations, understood as interdependent and multiple relations, matter for what

\section{The articles presented here demonstrate the attempt to broaden the field of application of principal- agent theory in science policy studies and brighten the interesting light this perspective can throw on the choices and procedures of science policy actors}

funding agencies are doing. Principal-agent relationships must therefore be understood in the light of these multiple and interdependent configurations, thus reinforcing Braun's finding.

Caswill takes seriously the idea of the contract that figures so prominently in principal-agent literature and embarks on a discussion of how the principal-agent relationship between funding agencies and scientists is organised by actual funding contracts. On the base of an exploratory, empirical study, he shows variations and similarities in how funding agencies set up contracts and attempt to monitor them. He confirms that funding agencies play a crucial role in "mediating" the harsh exigencies in the principal-agent relationship between politics and science. It turns out that the contracts are rarely monitored and that scientists have a considerable freedom to deal with these contracts.

On the other hand, one finds almost no 'shirking' by scientists, meaning there is seldom abuse of this freedom. This also confirms the interdependent relationship between funding agencies and scientists: above all, Caswill highlights, the scientific staff in funding agencies has an intrinsic interest in granting scientists sufficient freedom for action. Scientists, on the other hand, have an interest in complying with the funding agency to be sure of future resources.

Both Guston and Morris attempt to turn the usual top-down perspective of the principal-agent discussion around and take in a bottom-up perspective.

Guston analyses scientific advice as a form of "science in policy". In fact, one of the main problems for policy-makers is to know, given the often contradictory or competing advice different scientists may give, which advice to trust. This is, indeed, the problem of "adverse selection", which has rarely been treated in the context of science policy. He demonstrates that mediation and procedures as well as the creation of market-regulating mechanisms can be an effective way to overcome this problem.

Guston's study is, therefore, very much a debate on the "institutional design" of effective policy-making, only this time seen in the context of policyformulation. He points to the fact that principalagent is not a complete theory for scientific advice as such, but that it is very helpful in understanding 
the choices and procedures of organising the use of reliable knowledge in policy contexts.

Morris looks at the scientists, the agents in principal-agent theory, and wonders in what way they really behave as agents and how they experience the relationship with policy-makers as principals. By highlighting several "contextual features" of the scientific system, she is able to demonstrate that these features mitigate the sharp edges of the principalagent relationship. Because of these features among them, again, is the role of funding agencies - scientists have more freedom than we might expect, there are fewer conflicts between scientists and policy-makers, and accountability is less demanding than we might believe. These structural features allow scientists to do their work without feeling that they are merely agents.

Shove, finally, is the most critical with respect to principal-agent theory, because the experience with several research programmes has demonstrated that the means of principals' influence over scientists through research programmes is extremely limited. Rather, one finds an "anarchic structuring of the field". Shove conceptualises research programmes as the relationship among the funding agency, programme directors, and scientists as multiple agents. Neither funding agencies nor programme directors are able to inhibit the development of a dynamic of research programmes where scientists use these programmes for their own purposes, build up networks, and participate in a multitude of different programmes. These programmes are for her not agents, as she has presumed in the beginning, but they become their own actors. Principal-agent theory cannot, according to Shove, understand this turnaround and the dynamics that emerge within these programmes.

This overview not only demonstrates the attempt of the authors to combine theoretical rigour and 'requisite variety' but also the extension of topics to which principal-agent theory has been applied in science policy, though Shove sees some limitations in the approach. We could, however, question this conclusion, if we understand the relationship between programme directors and scientists as a relationship between a principal and multiple agents, and we use existing knowledge from the approach that underlines that such a constellation is only fruitful for the principal if the agents are in a competitive position. If, as is the case here, these agents play a co-operative game, it is not surprising that unique dynamics set in, and these agents use the opportunity structure of a research programme for their own purposes.

The articles in this special issue not only present the variety of topics that can be dealt with in terms of principal-agent theory, but they furnish also important insights such as:

- the importance of contextual features of the system that mitigate principal-agent relationships;
- the crucial role of funding agencies among these contextual features;

- the role of networks as a new way to organise principal-agent relations;

- the pertinence of the inclusion of users as the 'fourth actor';

- the conceptualisation of science policy in terms of configuration and not isolated bivariate principalagent relationships; and

- the usefulness of institutional design in the organisation of science policy.

We, therefore, are convinced of the usefulness of the approach and would invite other scholars to embark on this quest for a more analytical and rigorous tool in observing science policy.

\section{References}

Bates, R H, A Greif et al (1998), Analytic Narratives.(Princeton University Press, Princeton NJ).

Ben-David, J (1971), The Scientist's Role in Society. A comparative study.(Prentice-Hall, Inc, New Jersey).

Ben-David, J (1991), Scientific Growth. Essays on the Social Organization and Ethos of Science (University of California Press, Oxford).

Ben-David, J (1991 [1977]), "The central planning of science", in G Freudenthal (editor), Joseph Ben-David. Scientific Growth (University of California Press, Berkeley).

Bourdieu, P (1975), "The specificity of the scientific field and the social conditions of the progress of reason", Social Science Information, 14(6), pages 19-47.

Bourdieu, P (2001), Science de la science et réflexivité (Editions Raisons d'Agir, Paris).

Braun, D (1993), "Who governs intermediary agencies? Principalagent relations in research policy-making", Journal of Public Policy, 13(2), pages 135-162.

Caswill, C (1998), "Social science policy: challenges, interactions, principals and agents", Science and Public Policy, 25(5), October, pages $286-296$.

Coleman, J S (1990), Foundations of Social Theory (Belknap Press of Harvard University Press, Cambridge MA, London).

Daehle, van der W (1979), Geplante Forschung.(Suhrkamp TB, Frankfurt am Main).

Elgie, R (2002), "The politics of the European Central Bank: principal-agent theory and the democratic deficit", Journal of European Public Policy, 9(2), pages 186-200.

Ferejohn, J (1993), "Structure and ideology: change in Parliament in early Stuart England", in J Goldstein and R Keohane (editors), Ideas and Foreign Policy. Belief system, Institutions and Political Change (Cornell University Press, Ithaca).

Foray, D (2000), L'économie de la connaissance (La Découverte, Paris).

Ghiselin, M T (1987), "The economics of scientific discovery", in G Radnitzyk and $\mathrm{P}$ Bernholz (editors), Economic Imperialism. The Economic Approach Applied Outside the Field of Economics. (Paragon House Publishers, New York).

Gieryn, T F (1995), "Boundaries of science", in T J Pinch, Handbook of Science and Technology Studies (Sage, Thousand Oaks).

Guston, David H (1996), "Principal-agent theory and the structure of science policy", Science and Public Policy, 23(4), August, pages 229-240.

Guston, D H (2000), Between Politics and Science (Cambridge University Press, New York, Cambridge).

Huber, J, and A Lupia (2001), "Cabinet instability and delegation in parliamentary democracies", American Journal of Political Science, 45(1), pages 18-33.

Kiewiet, D R, and M D McCubbins (1991), The Logic of Delegation. Congressional Parties and the Appropriation Process (University of Chicago Press, Chicago).

Knorr, K D, R Krohn et al (1981), The Social Process of Scientific 
Investigation (D Reidel Publishing Company, Dordrecht).

Knorr-Cetina, K D(1981), The Manufacture of Knowledge. An Essay on the Constructivist and Contextual Nature of Science (Pergamon Press, Oxford).

Krohn, W, and G Küppers (1987), "Die Selbstorganisation der Wissenschaft", Science studies report no 33, Universität Bielefeld.

Latour, B (1987), Science in Action. How to follow scientists and engineers through society (Harvard University Press, Cambridge MA).

Latour, B, and S Woolgar (1979), Laboratory Life. The social construction of scientific facts (Sage, London).

Luhmann, N (1990), Die Wissenschaft der Gesellschaft (Campus, Frankfurt am Main).

Majone, G (2001a), "Nonmajoritarian institutions and the limits of democratic governance: a political transaction-cost approach", Journal of Institutional and Theoretical Economics, 157, pages 57-78.

Majone, G (2001b), "Two logics of delegation. Agency and fiduciary relations in EU governance", European Union Politics, 2(1), pages 103-121.

Mayntz, R (1991), "Scientific research and political intervention the structural development of publicly financed research in the Federal Republic of Germany", in F Orsi Battaglini and F Roversi Monaco (editors), The University within the Research System an International Comparison (Nomos, Baden-Baden).

McCubbins, M D (1984), "Congressional oversight overlooked: police patrols versus fire alarms", American Journal of Political Science, 28, pages 165-179.

Merton, R K (1970 [1938]), Science, Technology and Society in Seventeenth-Century England (Harper and Row, New York).

Miller, G J (1992), Managerial Dilemmas. The political economy of hierarchy (Cambridge University Press, Cambridge).

Moe, T M (1984), "The new economics of organization", American
Journal of Political Science, 28(4), pages 739-777.

Mukerji, C (1989), A Fragile Power. Scientists and the State (Princeton University Press, Princeton NJ).

Polanyi, M (1951), The Logic of Liberty.(Routledge and Kegan Paul, London).

Polanyi, M (1962), "The republic of science", Minerva, 1, pages $54-73$.

Rip, A (1994), "The republic of science in the 1990s", Higher Education Studies, 28, pages 3-32.

Rip, Arie, and Barend J R van der Meulen (1996), "The postmodern research system", Science and Public Policy, 23(6), December, pages 343-352.

Ross, S A (1973), "The economic theory of agency: the principal's problem", American Economic Review, 12, pages 134-139.

Strom, K (2000), "Delegation and accountability in parliamentary democracies", European Journal of Political Research, 37(3), pages 261-289.

Tullock, G (1966), The Organization of Inquiry (Duke University Press, Durham NC).

Van der Meulen, B J R (1998), "Science policies as principalagent games: institutionalization and path-dependency in the relation between government and science", Research Policy, 27, pages 397-414.

Weingart, P (1997), 'From 'Finalization' to 'Mode 2': old wine in new bottles", Social Science Information, 36(4), pages 591613.

Weingast, B E (1984), "The congressional-bureaucratic system: a principal-agent perspective (with application to the SEC)", Public Choice, 44, pages 147-191.

Williamson, O E (1975), Markets and Hierarchies (Free Press, New York).

Williamson, O E (1985), The Economic Institutions of Capitalism. Firms, Markets, Relational Contracting (The Free Press, New York). 